\title{
Abnormalities of systemic venous connections in pediatric patients undergoing congenital cardiac surgery
}

\author{
Muhammet Akyuz ${ }^{1}$, Onur Iş̧1 ${ }^{1}$, Ilker Mercan ${ }^{1}$, and Meltem Cakmak ${ }^{1}$ \\ ${ }^{1}$ Izmir Tepecik Training and Research Hospital
}

June 26, 2020

\begin{abstract}
PURPOSE: Systemic venous anomalies encompass a wide range of cardiovascular anomalies. Systemic venous anomalies are relatively infrequent and, under normal circumstances, asymptomatic, but may be clinical importance in cardiac surgery. This study aims to investigate whether systemic venous anomaly would have an effect on the any surgical planning. METHODS: We included a total of 525 consecutive patients (310 males, 215 females) who underwent open heart surgery for congenital heart disease. Patients were classified due to type of systemic venous anomalies. Demographic data and outcome data were retrospectively analyzed. RESULTS: Systemic venous anomaly was observed in $40(13,25 \%)$ patients. The mean age and weight of the patients was 11.5 months (range, 1 day to 18 years), $9.3 \mathrm{~kg}$ (range, $500 \mathrm{gr}-65 \mathrm{~kg}$ ) respectively. Preoperative diagnosis was obtained in $14 / 40(37.5 \%)$ patients with echocardiography, $12 / 40(30 \%)$ with computed tomography scan, in $7 / 40(17.5 \%)$ patients with conventional angiography and in 7/40 (17.5\%) patients during surgery. A persistent left superior vena cava is the most common systemic venous anomaly $(24 / 40(60 \%)$ patients) and in others IVC interruption, retroaortic innominate vein and connection of PSSVC-LA was determined $7 / 40$ patients $(17.5 \%), 4 / 40$ patients $(10 \%)$ and $4 / 40$ patients $(10 \%)$ respectively. No operative morbidity and complication associated with systemic venous anomalies was seen. CONCLUSION: Knowledge of the different course of the systemic venous anatomy prior to surgical intervention is important for the safe execution of any cardiac procedure.
\end{abstract}

\section{Hosted file}

Abnormalities of systemic venous connections.doc available at https://authorea.com/users/ 309400/articles/462778-abnormalities-of-systemic-venous-connections-in-pediatricpatients-undergoing-congenital-cardiac-surgery

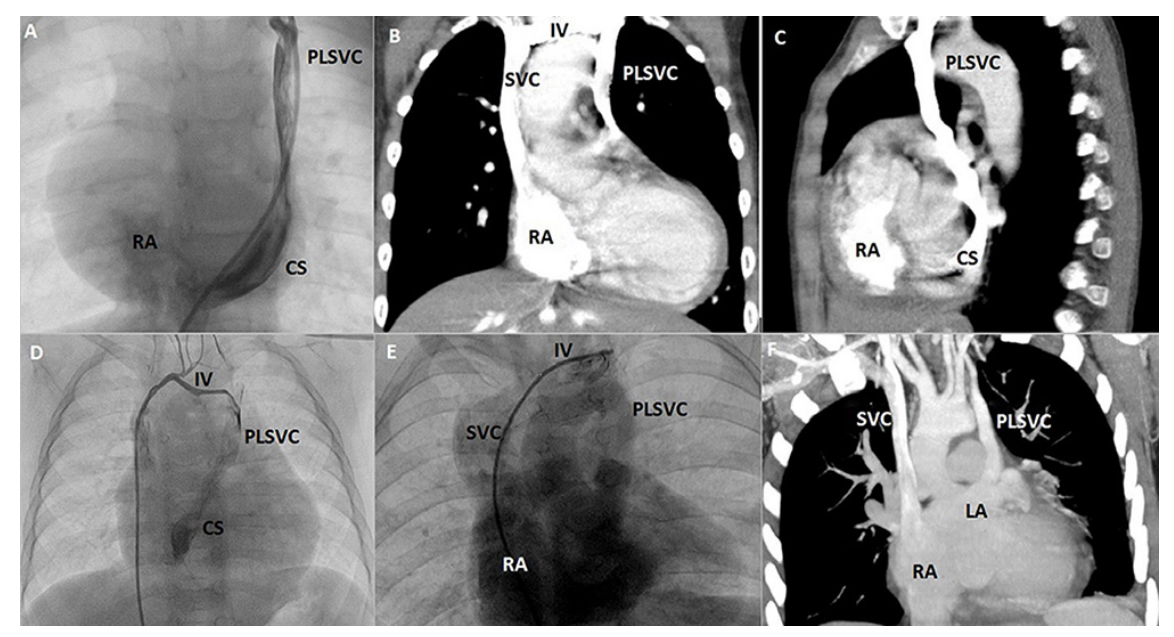



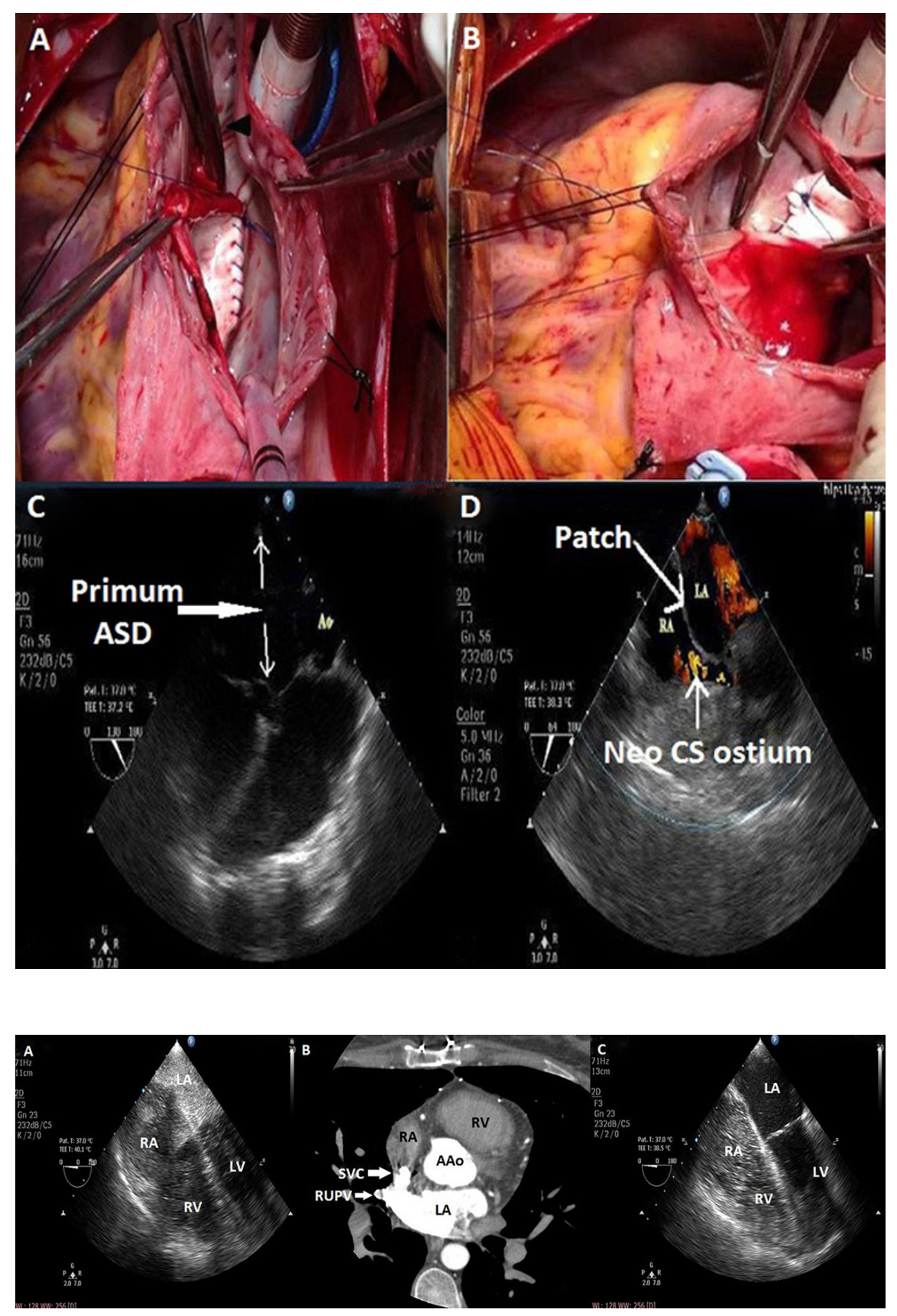

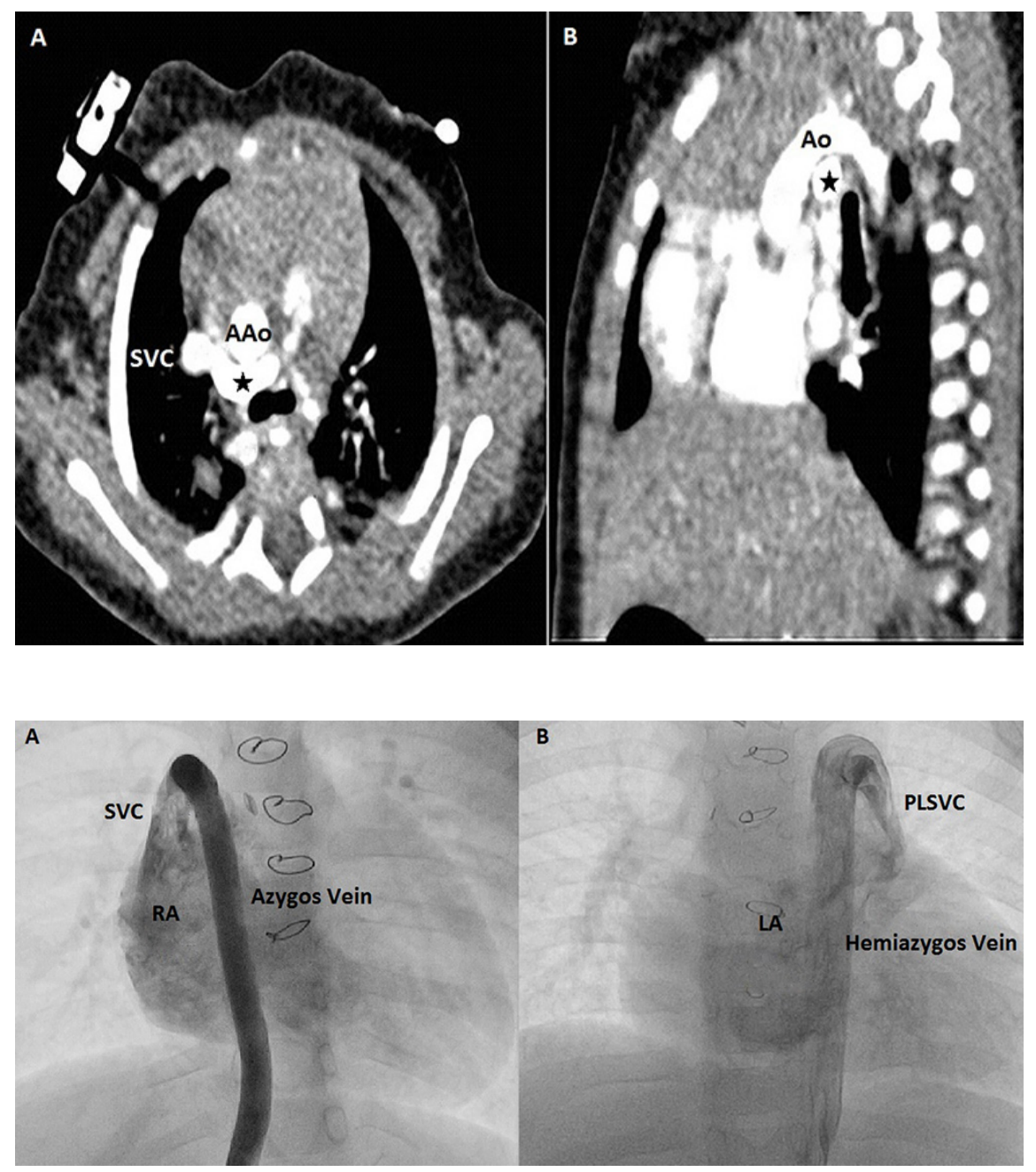